\title{
Globalization And Women: Challenges And Opportunities
}

Naierossadat Daneshvar Hosseini, (Email: daneshvar50@yahoo.com), Islamic Azad University, Iran

\begin{abstract}
There is growing evidence illustrating means in which a substantial number of women have been adversely affected by globalization, both absolutely as well as in relation to men. Women have also been more adversely affected during the increasing number of financial crisis generated by globalization while being disadvantaged by cuts in social protection. Women are more in danger in confronting the new global challenges. For example, they are disproportionately affected by different diseases, particularly AIDS. According to the UNAIDS epidemic update of 2003, 58 percent of HIV victims are female, and among the teenagers affected, 75 percent are girls. This paper will try to address the above issues while also discussing various positive impacts of globalization arguing that for many women, globalization has improved their economic and social status. Since people are most directly affected by globalization through their work and employment, many women workers have been absorbed into the global production system while wage employment has helped increase their incomes giving them greater potential economic independence and often raising their social status.
\end{abstract}

\section{INTRODUCTION}

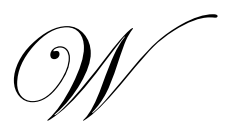

hile one interpretation of globalization has to do with equal exchange and sharing of goods and services between countries and cultures, the reality of a globalized world is much different. Globalization is a phenomenon that crosses and erases geographical and political borders and makes all countries start to look the same. As a result of globalization, local products, services, and cultures disappear into a global culture, a culture defined not by the global citizenry but rather the world's economic and political superpowers - mostly North America-owned corporations. Because of globalization, people on every continent are exposed to and consumed by a North American culture defined by Nike running shoes, MTV, Coca Cola, and McDonald's. Some people have re-named the process of globalization and called it McDonaldization or CocaColonization.

\section{WOMEN AND GLOBALIZATION}

The issue of women and globalization is one that concerns all mankind: men and women. The subject of globalization and its impact on women has been of considerable interest in most countries. Tackling this question reveals that two views are existent. The first considers that globalization has been a source of more pressures and responsibilities on women, while the second views globalization as a source of several advantages for women. In fact, both trends are bearing non-negligible traits of reality. The primary results of studies on globalization and women reveal two divert directions:

The first, believes that globalization will inflict more pressure and responsibilities on women, while others, believe that there are many positives or advantages for women. In the political field, some studies concluded that women's political role will be marginalized in developing countries; on the contrary, others conclude that political participation of women will be increased and that women issues will be in the center of human rights issues. As for the economic side, women will be excluded from the market because of their lack of skills and experience; and because of strong competition women will be marginalized and impoverished. On the contrary in western countries, where women have more experience and qualifications, they are expected to have more opportunities to compete in 
the market. Some social studies empathize that the role of women in raising children will shrink causing family system to break down. Other social studies come to the opposite conclusion.

\section{GLOBALIZATION, CULTURE AND, GENDER INEQUALITY}

In regards to culture, there are three main issues concerning women and globalization. The first concerns the relationship between the particularity of the national culture and the international thought, because of the growing international concern of women's issues and which dealt with this relationship and the different national identities. There is a contradiction between the two extremes, some consider international thought and culture as a form of alienation; others look at the cultural identity as a form of self -inclusion. This contradiction is considered one of the wide gaps that need to be overcome and reconciled. The second issue is how to encourage the moderate and openminded elucidation of the religious scripts. It is important to find continuous motives and incentives for religious interpretations in women issues. The third issue is the relationship between the future perspective of women's issues within the framework of globalization and the process of modernization of the society in a comprehensive way.

In some countries, globalization has resulted in serious gender imbalances. The extent of this imbalance depends largely on the level of gender equality prevailing in the norms, institutions, and policies of a country at the time when integration into the global economy takes place. In addition, women from different social groups in a particular country are affected differently. Nevertheless, in many developing countries deep-rooted and long-standing gender inequalities have meant that the social cost of globalization has fallen disproportionately on women.

There is a growing body of evidence illustrating the ways in which substantial a number of women have been adversely affected by globalization, both absolutely as well as in relation to men. For instance, trade liberalization has often allowed the import of subsidized agricultural products and consumer goods that have wiped out the livelihoods of women producers. The increased entry of foreign firms has often had a similar effect through, for example, displacing farming women from their land or out-competing them for raw materials essential to their productive activities. At the same time, women producers face formidable barriers to entry into new economic activities generated by globalization. This is often because of biases, either against women directly or against the micro- and small enterprise sector in which they predominate, in the policy and regulatory environment.

\section{WOMEN AND CONSUMPTION PATTERN}

Another negative impact of Globalization is spreading the culture of consumer entertainment through television, films, and advertisements, which serves big companies while destroying domestic social values and traditions. Globalization changes the consumption patterns of the family life and creates a tendency for unilateral consumption pattern. The problem of unlimited consumption is a problem facing households all over the world. Therefore, the question is how can we rationalize the consumption behavior of the household. Since unlimited consumption will deprive the next generations from their rights in consumption. Women can play a very important role in the rationalization of consumption as they are responsible for household expenditure and budget, but of course women alone can not do this. This emphasizes the importance of the role of all sectors of the state to help women rationalize domestic consumption.

\section{WOMEN IN AGRICULTURAL SECTOR}

Economic globalization - the process of opening up regional markets for global consumption - has played a major role in the transformation of agriculture from family gardens to a huge industry characterized by agribusinesses. Commercialized agriculture relies just as heavily on the work of women as did the family farm. "Women are cogs in the machine of a globalized agriculture industry: picking tomatoes in Mexico, harvesting rice in India, planting tea in Uganda, packing peaches in Ontario and fish in Nova Scotia. But while women still play a role in agricultural production, women's control over the means of food production has been significantly weakened. The forced migration, environmental contamination, and hunger that have resulted from this transformation, have been 
devastating." 1

Globalization has also severely impacted women's relationship to food and the production of food. The liberalization of trade and the subsequent global spread when inequalities between countries become greater, of a market economy has forced many impoverished countries to stop growing food for themselves in favour of growing food for export. As mentioned this has led to greater food insecurity, reduced nutrition, and has moved women in exporting countries into low-paying, undervalued agricultural work.

\section{WOMEN IN INDUSTRIAL SECTOR}

The increase of industrial exports in developing countries was accompanied by an increase in the demand for female employment, because industrialization under the present international conditions in the developing countries depended on female labour. Therefore, the new female employment opportunities depended on the expansion of industrial export. The participation of women in the industrial sector was much higher than on the national level in the formal sectors, and in the industrial sector female employment was concentrated in the export sector. Empirical evidence proved that industrialization in low income countries depended on women, just like export production; and that the increase in the income of many women is due to the expansion of trade. The expansion of export industries was the main reason for women to enter the market economy. For example, the number of the fabric factories in Bangladesh, increased from four factories in 1978 to 2400 factories in 1995, with 1.2 million workers, $90 \%$ of them women under the age of 25. Many other countries share the same experience such as, Indonesia, Tunisia, and Taiwan to name a few.

\section{WOMEN IN THE SERVICE SECTOR}

The Service sector offers regular paid contract jobs to women more than any other sector. This increases women's employment opportunities, which is strongly connected to their contribution to family expenses especially for education and health of their children. Women's income support the creation of new human resources and raises the level of human development.

The service sector is considered one of the strongest sectors at the present time, as it clearly expanded very rapidly to the extent that it is getting more similar the progress achieved by the industrial sector, specially in the field of communication and information technology The service sector includes many activities, starting from domestic services and small trade, government administration, social service sector (education and health), and project services (accounting, counseling services, law and information processing). This sector is considered the largest sector of all the economic sectors in terms of its output, and the employment opportunities which it provides in many countries. Working in the service sector especially small businesses is considered the most important income source for the poor women.

Modern information and communication technology, especially the Internet, and the growing transcontinental employment opportunities brought about many new opportunities for women. However women who will benefit from these advantages are mostly those who are well educated and who belong to high-income classes, while women who are not well educated or are illiterate are marginalized, usually these are over 35 years old and are working in sectors which suffer from declining demand.

Although technology is increasing the number of women working in the information and communication sector, and the wide rapid development of this technology in all possible languages, mean that poor people specially women in developing countries face the danger of being left out of production or knowledge and information exchange, and in many other aspects of life.

A negative impact is the very limited employment opportunities that this sector offers to poor women who are not educated, compared to those offered by the industrial and the agricultural sectors. On the other hand, the

\footnotetext{
${ }^{1}$ from the Women \& the Economy Website: www.unpac.ca/economy/index2.html
} 
picture is different, if we focus on the gender gap in earnings in open semi-industrialized economies. Economic growth was higher where the gender gap in earnings was higher. This shows that various forms of growth do not diminish gender gaps in the labour market, even though the absolute incomes of women may increase. Again in open economies where capital is highly mobile, policies that successfully promote greater autonomy for women can lead to an increase in national income; but those that increase women's bargaining power in the workplace can have a negative impact on national output if the response of capital is to move to other locations.

The International Monetary Fund and the World Bank encourage developing countries to use export-led growth to expand their economies. Such globalized economies require a labor force of a size that must include women, but women's employment varies greatly by region. For example, 74 percent of women are in the work force in East Asia, the greatest proportion among all regions of the world, and they participate for the longest part of their lives in comparison to other regions. In the Middle East and North Africa, however, only about 34 percent participate, while women in the Middle East drop out of the labor force in great numbers when they marry and have children. In many cases, cultural barriers, especially in the relationship between women and men within households, impede increased economic participation, or undermine the quality of that participation. For example, even women who do work face differential treatment such as wage gaps and segregation into traditionally female industries. Women have historically born the burden of non-monetized labor, such as child care and domestic work. Increased participation in the work force also implies increased hazards for women, however. Women's jobs outside the home tend to be the worst compensated, least secure, and most dangerous available in the economy, especially in periods of recession in most developing countries. For example, gaps in labor laws, or ignorance and lack of enforcement of the labor codes in practice, allow for the exploitation of women. Women have only a precarious claim on the rights to minimum wage, work-week length, leave time, health care under the national social security system, and privacy protections. Often, they are subject to physical and/or sexual abuse, according to Human Rights Watch. Unfortunately, even the global nature of business does not confer universal rights for these women.

\section{WOMEN IN INFORMAL SECTOR}

In most developing countries there is a large informal economy, where economic activity lacks recognition and protection under formal legal or regulatory frameworks. It typically consists of small-scale manufacturing, services or vending in urban areas, domestic work or agricultural work on small plots of land. In many of the lowestincome countries it accounts for the large majority of workers. There is often a high proportion of women workers. This work is very diverse, from small enterprises to survival activities, including not only the self-employed and family workers but also wage labour in many forms. Typically such activities are of low productivity, and poverty levels among informal workers are high. But there is also a large reservoir of entrepreneurship and innovation. Informal work is less prominent in industrialized countries, but by no means absent, and includes the informalization of previously secure wage employment.

At the Lisbon European Council in March 2000, the European Union set itself a new strategic goal for the next decade: to become the most competitive and dynamic knowledge-based economy in the world, capable of sustainable economic growth with more and better jobs and greater social cohesion The goal must be to make these informal activities part of a growing formal sector that provides decent jobs, incomes and protection, and can trade in the international system. This will be an essential part of national strategy to reduce poverty. That means increasing assets and productivity, appropriate regulatory frameworks, raising skills and ensuring that policy biases are removed. Policies to deal with the lack of recognition of qualifications and skills, and the exclusion of informal workers from social security and other protections are particularly important. The same are policies to improve the distribution of assets, and especially to increase access for self-employed women and men and small businesses to financial resources, technology and markets, and to increase opportunities for investment. But most workers and economic units in the informal economy have difficulty accessing the legal and judicial system to enforce contracts, and their access to public infrastructure and benefits is limited. A variety of bureaucratic and other restrictions create barriers and difficulties which hinder formalization, growth and sustainability.

The relation between both formal and informal sectors is explained by the fact that small workshops produce production inputs to the big factories. The scope of this cooperation and integration is very difficult to evaluate as it 
varies from time to time and from one industry to another and from one season to another. Many argue that in the process of globalization demand for female employment has increased in the informal sector, through subcontracts with the formal sector. The role and importance of the informal sector in economic activity has increased in the developing countries especially for women, however a high ratio of these women are working without any contracts.

\section{WOMEN AND FLEXIBILITY AT WORK}

While flexibility can be attractive for workers when it meets the needs desire of the workers, but in reality this flexibility does not benefit women workers because it has created an environment of part-time work, sub contracting, temporary, and casual employment. These forms of work are increasing in industrialized countries and although they affect both men and women, it is substantially women who are employed in this insecure sector. Far from legislating to protect workers from such insecurity, some governments have actually encouraged this type of flexibility as being good for industry. This requirement for flexibility also extends to working hours where in practice it means that women are often required to meet unreasonable attendance schedules at short notice.

\section{CONCLUSION}

Globalization offers women unprecedented opportunities, but equally new and unique challenges. Gender inequality exacerbated by the effects of globalization. The paper argues that globalization creates many challenges for women in different economic sectors and a substantial number of women have been adversely affected by globalization, both absolutely as well as in relation to men. Women have additional vulnerabilities, especially malnutrition, sexually transmitted diseases, pregnancy complications, domestic violence, sexual abuse. In many cultures, women are the first to take care of the vulnerable, sick, and dying and the last to receive preventative or life saving treatment. In order to alleviate these problems, public education programs can promote healthy lifestyles, eliminate gender discrimination, access to services, and prioritize the help for women.

The paper argues that for many women, globalization has resulted in an improvement in their economic and social status. Many women workers have been absorbed in to the global production system and the wage employment gives them higher incomes than their previous situations and also gave them a greater potential economic independence and often raises social status. Progress toward eliminating gender inequality in the future depends on finding and embracing the occasions, mostly in the political and legal realm, where the global approach strengthens women's security and welfare, and fighting the issues, mostly in the economic realm, where women are made worse off by the new global system. This paper concludes that the new global system has not been to the benefit of the women. The negative impact of Globalization particularly in terms of gender inequality is much more than its positive impacts.

\section{REFERENCES}

1. Allmendinger, J. (1989): Educational system and labour market outcomes. European Sociological Review 3. 231-250.

2. Brown, T. (1999). Challenging globalization as discourse and phenomenon. International Journal of Lifelong Education, 18(1), 3-17.

3. European Commission (2001), Employment in Europe Report, European Commission, Brussels, Belgium, http://europa.eu.int/comm/dgs/employment_social/pub_en.htm

4. ILO (2001), World Employment Report, International Labour Office, Geneva, Switzerland, www.ilo.org

5. ILO (2001) Decent Work for Women, Bureau for Gender Equality Breaking through the glass ceiling, International Labour Office, Geneva, Switzerland, www.ilo.org/public/english/bureau/gender

6. National Council for Women (2001), Women and Globalization Seminar, Cairo, May 2001

7. Scott, Catherine V. (1995), Gender and Development. Boulder, Colorado: Lynne Rienner, UNDP (1999), Human Development Report, 1 New York, Oxford University Press.

8. UNDP(2001), Human Development Report, United Nations Development Program, New York, USA, www.undp.org

9. UNI (2001), UNI for People in the Changing Economy, Union Network International (UNI), Nyon, 
Switzerland, www.union-network.org

10. UNIFEM (2000), Progress of The World's Women, UNIFEM Biennial Report. Dianne Elson, Coordinator. New York.

11. UNCTAD (1999), Trade, Sustainable Development and Gender. UN, New York and Geneva, 1999.

12. World Bank (2001), Gender and the Digital Divide, The World Bank Group, Gender and the Digital Divide Seminar Series, www.worldbank.org/gender/info/digitaldivide

\section{NOTES}

